tity of "betterness" or "worseness" in an ingot being added to or subtracted from the weight of it, gives the quantity of standard metal container in it," and that therefore the "betterness" or "worseness" affords a ready means of determining the amount of copper or gold required to standardise the whole. Further, if a number of ingots of varying weights and fineness have to be dealt with, a similar result will be arrived at by taking the algebraical sum of the several products of their weights and "betterness" or "worseness." These advantages, however, apply to individual calculations, and become unimportant when standarding tables adapted to the decimal system are available.

In a letter to Mr. Fremantle, Prof. Roberts advocated the abolition of this old system of carats and grains and the adoption of the decimal system. This has accordingly been carried into effect. Gold of the value of two millions sterling has recently been imported for coinage, and the simplicity and accuracy of the new system has been abundantly demonstrated.

The facts above stated may seem comparatively unimportant in themselves, but the Mint may at any time be called upon to coin (as was the case in 1872) fifteen millions sterling of gold in a single year, and extreme care has to be taken to insure accuracy in the standard fineness of the metal. It is curious that the old system described above should not have given place before now to that which has long been adopted in other countries.

\section{THE POISONOUS LIZARD"2}

THE Gila Lizard of Arizona and Sonora has anterior, deciduous, grooved teeth, which communicate by ducts with large glands within the angle of th. Jwer jaw - an apparatus so strongly resembling the poison-fangs of serpents as to suggest that this lizard has venomous properties. It is said by the natives of Mexico to be very poisonous, but others again have declared that it is perfectly harmless. One specimen sent to Sir John Lubbock killed a frog in a few minutes and a guinea-pig in three minutes.

The conflicting statements are probably due to the fact that the teeth are very small and easily removed. Some specimens of the creature reach the length of three feet. As experiments made by allowing the lizard to bite animals are untrustworthy on account of the uncertainty of getting the poison equally introduced into the tissues at every bite, Doctors Weir Mitchell and Reichert collected the saliva so as to be able to inject it in known quantities. The saliva was obtained by making the animal bite on a saucer-edge. It dropped in small quantities from the lower jaw, and had a faint and not unpleasant aromatic odour. It was distinctly alkaline, in contrast to serpent venoms, which are all alike acid. Four and a half minims of it diluted with half a cubic centimetre of water and injected into the breast of a large pigeon caused the bird to walk unsteadily after three minutes. At the same time the respiration became rapid and short, and at the fifth minute feeble. At the sixth minute the bird fell in convulsions with dilated pupils, and was dead before the end of the seventh minute. There was not the least trace of any local effect of the poison, as there would have been in the case of crotalus venom. The muscles and nerves were perfectly sensitive to stimulation mechanically or by weak induced currents. The heart was arrested in complete diastole, and was full of firm, black clots. The intestines looked congested. In another experiment it was found that the poison gradually

I Tables on the system above described were first published in the year 165I, having been prepared by Mr. Reyn jlds, Assay Master at the Mint in the Tower A second edition was afterwards issued with corrections and

additions in 1677 . A Partial Study of the Poison of Heloderma suspectum (Cope), the Gila Monster." "By Dr. S. Weir Mitchell and Dr. E. T. Reichert of
Philadelphia. lowered the arterial tension and rendered the pulse irregular. Its action on the pulse is not due to any effect upon the pneumogastric nerves, as it is just the same when these nerves are cut. When applied to the heart of a frog it arrests its pulsations in diastole, and the organ afterwards contracts slowly-possibly in rapid rigor mortis. The cardiac muscle loses its irritability to stimuli at the time it ceases to beat. The other muscles and nerves respond reatily to irritants, but the spinal cord has its power annihilated abruptly and refuses to respond to the most powerful electrical currents.

The authors conclude that "this interesting and virulent heart poison contrasts strongly with the venoms of serpents, since they give rise to local hemorrhages, and cause death chiefly through failure of the respiration and not by the heart, unless given in overwhelming doses. They lower muscle and nerve reactions, especially those of the respiratory apparatus, but do not as a rule cause extreme and abrupt loss of spinal power. Finally, they give rise to a wide range of secondary pathological appearances which are absent from Heloderma poisoning."

This distinction between the action of the poison of Heloderma and serpent venom is correct as far as regards the poison of the rattlesnake and perhaps also the Crotalidæe generally, but the distinction is by no means marked between the poison of Heloderma and the venom of the cobra. This venom was found by Sir Joseph Fayrer and Dr. Lauder Brunton to have but a slight local action as contrasted with that of the rattlesnake or of the daboia, and to produce no local hernorrbage. The effect of cobra poison on birds also is very much the same as that of the Heloderma; and in the experiments given in this preliminary paper, the effect of the Heloderma poison on the heart of the frog is very much like that of cobra poison, the failure of action with subsequent and gradually increasing contraction being almost precisely the same. ${ }^{1}$

In Brunton and Fayrer's experiments on cobra poison, the fall of blood-pressure was less marked, but it still occurred. Paralysis of the spinal cord also is produced by cobra poison, and the experiments in this preliminary paper are too few to enable us to decide whether the paralysing effect is greater from the poison of Heloderma than from cobra venom. We shall look with much interest to the further study of the venom of this curious animal, which the authors intend to make on the arrival of the fresh specimens which they are about to receive.

ON THE CONDENSATION OF VAPOUR FROM THE FUMAROLES OF. THE SOLFATARA OF POZZUOLI

THE fumaroles of the Solfatara of Pozzuoli, and especially the larger fumarole known as the Bocia della Solfatara, give a striking illustration of the action of smoke in causing the condensation of aqueous vapour in the manner demonstrated by the experiments of Coulier, and more especially by those of Dr. Aitken.

Persons who have visited the Solfatara will remember that one of the feats by which the ciceroni of the place try to excite the wonderment of visitors is to light some paper or a few dry branches, and put the flaming body before or inside the mouth of the principal fumarole, augmenting thus very greatly the volumes of cloudy vapour escaping from the fissure. This phenomenon can be observed in all volcanic fumaroles. A flame is not indispensable, the condensation of the vapour being also produced by the mere smouldering of tinder.

Prof. Piria first tried to explain the phenomenon. $\mathrm{He}$ thought that small quantities of sulphuretted hydrogen issued from the soil together with the aqueous vapour:

I Brunton and Fayrer on the Poison of Indian Venomous Snakes (Roy. Soc. Proceedings, January 22, 1874, p. 126). 
on mixing with air and coming in contact with a flame, or an incandescent body, the hydrogen sulphide would be oxidised, and resolved in sulphur and water (with the production of small quantities of sulphur dioxide); the sulphur, minutely divided, would remain long suspended in air, and cause the condensation to cloudy consistency of the aqueous vapour. Piria illustrated his explanation by a simple experiment : if in a vessel containing a mixture of sulphuretted hydrogen and air a lighted taper is introduced, a dense mist is rapidly formed; a similar mist is produced when glowing charcoal, or highly beated lava, or pumice, or glass, or red-hot iron is introduced in the gaseous mixture. When there is a large proportion of $\mathrm{H}_{2} \mathrm{~S}$, the oxidation is very rapid, and the mixture explodes and burns.

Piria's explanation cannot be applied to the Bocca della Solfatara, where the presence of $\mathrm{H}_{2} \mathrm{~S}$ cannot be detected either by the sense of smell, or by the leadacetate test-papers. In the "Memorie Geologiche sulla Campania (Rendiconti della Reale Accademia delle Scienze di Napoli, i 849 , p. 137) Prof. A. Scacchi, after having opposed Piria's opinion, gives the following explanation: "I believe the increase of the vapoury cloud due to the carbonic acid produced in the combustion of the tinder, its affinity for water causing the precipitation of the invisible vapour, and thus producing a mist." According to Prof. Scacchi, in the presence of large quantities of aqueous vapour, and at the temperature of the fumarole, carbonic dioxide would act as hydrochloric acid gas which fumes in ordinary air.

Since 1849 no one (as far as I have gathered) has suggested any new opinion or tried some experiment to explain the phenomenon in question. I thought it would be interesting to test experimentally at the Solfatara the opinion of Prof. Scacchi. I was inclined to believe that, if at the ordinary temperature carbonic dioxide does not condense aqueous vapour from the air, there was very little probability that the condensation would be caused at temperatures as high as those of the vapours issuing from the Bocca of the Solfatara (about $90^{\circ}$ Centigrade externally); the action of flames or smouldering bodies in augmenting the vapoury cloud appeared to me as chiefly due to the condensation around the minute particles of soot or dust produced during the combustion.

The following experiments were done during a clear day, when abundant vapours were issuing from the large fumarole :-

I. A Wolff bottle (I litre capacity), from which a constant current of carbon dioxide was obtained (by pouring dilute hydrochloric acid on marble fragments), was placed on the ground inside the fumarole. The cloud of vapour augmented.

2. By means of a caoutchouc tube the $\mathrm{CO}_{2}$ from the generator was conducted near the hottest invisible vapour. This vapour became interspersed with cloudlets of condensed vapour, and the cloudy pillar outside the Bocca greatly augmented.

3. A large bottle (of about 15 litres capacity) filled with carbon dioxide was brought inside the cavity, and the $\mathrm{CO}_{2}$ poured out. The effect was most striking outside by the voluminous, but not immediate, outbursts of cloudy vapour.

4 With bellows of the kind used for sulphuring vines, I blew sulphur dust inside the cavity. This caused the production of great volumes of visible vapour. The same effects were produced every time that minutely divided bodies (wheaten flour, oxide of magnesia, chalky dust, \&c.) were blown, or thrown, inside the cavity or near the invisible vapour.

5. The effect was very striking when the action of the carbon dioxide (from the Wolff bottle) was combined with the action of the sulphur dust.

6. A small alcohol flame augmented the cloudiness of the vapour.
7. The smoky flame of burning naphthalene acted much more powerfully than the alcohol flame.

From these experiments, which (with the exception of 3 and 6) were often repeated, the following conclusions may be drawn :-

I. Carbon dioxide helps to condense watery vapour.

2. Minute bodies suspended in air are a powerful cause (the principal cause, as Coulier and Aitken have shown) in the condensation of aqueous vapour.

3. The action of flames, or of incandescent bodies, in augmenting so remarkably the volumes of visible vapour rising from the fumaroles of the Solfatara must be ascribed both to the carbon dioxide and to the minute carbonaceous particles set free during the combustion.

of these conclusions the first requires to be confirmed by careful laboratory experiments. ITALO GIGLIOLI Laboratory of Agricultural Chemistry, R. Agric. College, Portici

STATE OF THE ATMOSPHERE WHICH PRODUCES THE FORMS OF MIRAGE OBSERVED $B Y$ VINCE AND BY SCORESBY

IN I88I, when I wrote the article Light for the Encyc. Britt., I had not been able to meet with any detailed calculations as to the probable state of the atmosphere when multiple images are seen of objects situated near the horizon. I had consulted many papers containing what are called "general" explanations of the phenomena, but had found no proof that the requisite conditions could exist in nature :-except perhaps in the case of the ordinary mirage of the desert, where it is obvious that very considerable temperature-differences may occur in the air within a few feet of the ground. But this form of mirage $i$ essentially unsteady, for it involves an unstable state of equilibrium of the air. In many of Scoresby's observations, especially that of the solitary inverted image of his father's ship (then thirty miles distant, and of course far below the horizon), the details of the image could be clearly seen with a telescope, showing that the air must bave been in equilibrium. The problem seemed to be one well fitted for treatment as a simple example of the application of Hamilton's General Method in Optics, and as such I discussed it. The details of my investigation were communicated in the end of that year to the Royal Society of Edinburgh, and will, I hope, soon be published. The paper itself is too technical for the general reader, so that I sball here attempt to give a sketch of its contents in a more popular form. But a curious little historical statement must be premised.

It was not until my calculations were finished that I found a chance reference to a great paper by Wollaston (Phil. Trans. I 80o). I had till then known only of Wollaston's well-known experiment with layers of different liquids in a small vessel. But these, I saw, could not reproduce the proper inirage phenomena, as the rays necessarily enter and emerge from the transition strata by their ends and not by their lower sides. This experiment is by no means one of the best things in Wollaston's paper, so far at least as the immediate object of the paper is concerned. That so much has been written on the subject of mirage during the present century, with only a casual reference or two to this paper, is most surprising. It may perbaps be accounted for by the fact that Wollaston does not appear to have had sufficient confidence in his own results to refrain from attempting, towards the end of his paper, a totally different (and untenable) hypothesis, based on the effects of aqueous vapour. Be the cause what it may, there can be no doubt that the following words of Gilbert were amply justified when they were written, early in the present century :- "In der. That ist Wollaston der Erste und Einzige, der die Spieglung aufwärts mit Glück zu erklären unternommen hat." For his methods are, in principle, perfectly correct and suffi- 